\title{
Effect of coincident enterovirus infection and cows' milk exposure on immunisation to insulin in early infancy
}

\author{
O. Vaarala ${ }^{1}$, P. Klemetti ${ }^{1}$, S. Juhela ${ }^{1,2}$, O.Simell ${ }^{3}$, H.Hyöty ${ }^{4}$, J. Ilonen ${ }^{2}$ \\ ${ }^{1}$ Department of Molecular Medicine, National Public Health Institute, Biomedicum, Helsinki, Finland \\ ${ }^{2}$ Department of Virology, University of Turku, Turku, Finland \\ ${ }^{3}$ Department of Pediatrics, University of Turku, Turku, Finland \\ ${ }^{4}$ Department of Virology, University of Tampere, Tampere, Finland
}

\section{Abstract}

Aims/hypothesis. Insulin autoantibodies appear often as the first autoantibody in children who develop islet-cell autoimmunity. Our recent studies indicate that primary immunisation to insulin is induced in early infancy by exposure to dietary bovine insulin present in cows' milk formulas. As gut-associated lymphoid tissue is also the primary replication site of enteroviruses, we tested whether enterovirus infections could modify the development of immune response to dietary insulin in early infancy.

Methods. We studied the development of IgG-antibodies to dietary bovine insulin by enzyme immunoassay in relation to enteroviral infections determined by T-cell proliferation response to the Coxsackie B4 virus and by serological tests for enterovirus antigens in 57 infants who carried the HLA $D Q B 1 * 02 / 0302$ diabetes risk genotype and participated in a Finnish population-based birth-cohort study
(Diabetes Prediction and Prevention Project, DIPP, study).

Results. In the infants exposed to cows' milk formulas before the age of 3 months, those who had a T-cell proliferation response to enterovirus antigen at 3 months of age $(n=12)$ had higher concentrations of IgG-antibodies to bovine insulin at the age of 6 and 9 months than those who did not have T-cell proliferation response to enterovirus antigen $(n=25)$ (median OD were 0.742 vs $0.427, p=0.04$, and 0.477 vs $0.293, p=0.02$, respectively).

Conclusion/interpretation. Our results suggest that two epidemiological risk factors of Type I (insulin-dependent) diabetes mellitus, enterovirus infections and exposure to cows' milk formulas, could modify the immunisation to insulin in early infancy. [Diabetologia (2002) 45:531-534]

Keywords Bovine insulin, cows' milk, enterovirus, coxsackievirus, oral tolerance, dietary antigen.
Immunisation to insulin is associated with autoimmune diabetes. In non-obese diabetic (NOD) mice insulin-reactive T-cells infiltrate the islets and induce diabetes when transferred to healthy recipients [1]. Insulin autoantibodies (IAA) appear often as the first autoantibody in children who develop islet-cell auto-

Received: 16 May 2001 and in revised form: 17 December 2001

Corresponding author: O. Vaarala, Department of Molecular Medicine, National Public Health Institute, Biomedicum, P. O.Box 104, 00251 Helsinki, Finland

e-mail: outi.vaarala@ktl.fi

Abbreviations: IAA, Insulin autoantibodies; EIA, enzyme immunoassay; DIPP, Diabetes Prediction and Prevention Project immunity [2]. Our studies suggest that primary immunisation to insulin is induced in early infancy by exposure to dietary bovine insulin present in cows' milk formulas $[3,4]$.

Enteroviral infections have been associated with the development of islet-cell autoimmunity in prospective studies [5]. Our observation on the immunisation to dietary insulin indicates that the first immunisation to insulin occurs in the gut-associated lymphoid tissue. As gut-associated lymphoid tissue is also the primary replication site of enteroviruses, it is possible that enterovirus infections could modify the development of immune response to dietary insulin in early infancy.

We studied the development of IgG-antibodies to bovine insulin in relation to enteroviral infections de- 
termined by T-cell proliferation response to coxsackie $\mathrm{B} 4$ virus and by serological tests for enterovirus antigens in 57 infants who carried $H L A D Q B 1^{*} 02 / 0302$ diabetes risk genotype and who participated in a Finnish population-based birth-cohort study (DIPPstudy). In the infants exposed to cows' milk formulas before the age of 3 months those who had a cellular response to enterovirus antigen at 3 months of age $(n=12)$ had higher concentrations of IgG-antibodies to bovine insulin at the age of 6 and 9 months than those who did not have a cellular response to enterovirus $(n=25)$. Our results suggest that enterovirus infections in early infancy modify the immune response to insulin.

\section{Subjects and methods}

Subjects. A group of 57 infants, selected for carrying $H L A$ $D Q B 1 * 02 / * 0302$ genotype and enrolled in the Finnish birthcohort survey, the Diabetes Prediction and Prevention (DIPP) Project between March 1995 and November 1996, were studied for T-cell response to enteroviruses at 3 and 6 months of age. This study has been approved by the Joint Ethics Committee of Turku University and Turku University Hospital. Informed consent was obtained from all the parents or guardians of the participants. The feeding data on the duration of exclusive breast-feeding and start of formula feeding were registered sequentially at each study visit at ages 3,6 , and 9 months. Group 1 included 16 infants ( 6 female) who were fully breast fed, Group 2 included 25 (15 female) who received cows' milk formula, as supplementation during breast feeding, and Group 3 included 12 infants ( 6 female) who were not breast-fed at all but received cows' milk formula at the age of 3 months. At the age of 6 months the information of the diet was available from 51 infants and only one infant was fully breast-fed. IgG-class bovine-insulin binding antibodies and virus-specific antibodies were measured in plasma samples taken at the age of 3, 6, 9 and 12 months.

T-cell proliferation test to coxsackie B4 virus. A total of 50000 peripheral blood derived mononuclear cells (PBMC) per well in $200 \mu \mathrm{l}$ were incubated in quadruplicates with antigen for 6 days in RPMI 1640-10\% human AB-serum (Finnish Red
Cross, Helsinki, Finland), glutamine, HEPES and gentamycin. Tritiated thymidine $(2 \mu \mathrm{Ci} / \mathrm{ml}$, Amersham, UK) was added $18 \mathrm{~h}$ before harvesting and incorporated radioactivity was measured. Stimulation indices were calculated by dividing the median counts per min (cpm) value of antigen stimulated wells by the median cpm of wells with medium only. Purified coxsackievirus B4 virus (ATCC) was used at a $1 \mu \mathrm{g} / \mathrm{ml}$ concentration. The preparation of purified coxsackievirus antigen was made by sucrose gradient centrifugation.

Assays for virus-specific antibodies. IgG and IgA class enterovirus antibodies were measured against purified coxsackievirus B4 and echovirus 11 using enzyme immunoassay (EIA) [5]. Virus antigens were heat-treated to expose antigenic determinants which are cross-reactive between different enterovirus serotypes.

EIA for bovine insulin-binding antibodies was carried out as described $[3,4]$. A $p$ value below 0.05 was considered significant.

\section{Results}

The relation of cows' milk formula exposure and bovine-insulin-binding antibodies. At the age of 3,6 and 9 months the concentrations of IgG-antibodies to bovine insulin were higher in the infants who were exposed to cow's milk formulas before the age of 3 months (Groups 2 and 3 ) than in the infants who were fully breast fed (Group 1) (Table 1). At the age of 12 months the differences between the three groups disappeared.

The relation of bovine-insulin-binding antibodies and $T$-cell responsiveness to coxsackie B4 virus. Information on the dietary history and T-cell proliferative response to coxsackie B4 virus was available from 53 infants at the age of 3 months. Positive proliferation response to coxsackie B4 (SI $\geq 3$ ) was found in 17 of the 53 infants $(32 \%)$ at 3 months of age. Infants who had a positive proliferation response to coxsackie B4 as an indicator for enterovirus infection during the first

Table 1. The concentrations of bovine-insulin-binding IgG-antibodies at different ages in the infants grouped according to their exposure to cows' milk (CM) formulas at 3 months of age

\begin{tabular}{|c|c|c|c|c|}
\hline & $\begin{array}{l}3 \text { months median (IQR) / } \\
\text { mean (SD) }\end{array}$ & $\begin{array}{l}6 \text { months median (IQR) / } \\
\text { mean (SD) }\end{array}$ & $\begin{array}{l}9 \text { months median (IQR) / } \\
\text { mean (SD) }\end{array}$ & $\begin{array}{l}12 \text { months median (IQR)/ } \\
\text { mean (SD) }\end{array}$ \\
\hline Group 1 (BF) & $0.142(0.207) / 0.281(0.341)$ & $0.270(0.457) / 0.422(0.404)$ & $0.324(0.282) / 0.277(0.151)$ & $0.315(0.250) / 0.384(0.217)$ \\
\hline $\begin{array}{l}\text { Group } 2 \\
(\mathrm{BF}+\mathrm{CM})\end{array}$ & $\begin{array}{l}0.206(0.214) / 0.290(0.214) \\
\text { vs group 1 NS }\end{array}$ & $\begin{array}{l}0.427(0.394) / 0.531(0.301) \\
\text { NS }\end{array}$ & $\begin{array}{l}0.293(0.361) / 0.336(0.186) \\
\text { NS }\end{array}$ & $\begin{array}{l}0.453(0.293) / 0.484(0.362) \\
\text { NS }\end{array}$ \\
\hline Group $3(\mathrm{CM})$ & $\begin{array}{l}0.497(1.083) / 0.820(0.598) \\
\text { vs group } 1: p=0.001\end{array}$ & $\begin{array}{l}0.609(0.379) / 0.633(0.297) \\
p=0.042\end{array}$ & $\begin{array}{l}0.517(0.479) / 0.680(0.354) \\
p=0.001\end{array}$ & $\begin{array}{l}0.382(0.450) / 0.574(0.473) \\
\text { NS }\end{array}$ \\
\hline All groups & $p=0.002$ & $p=0.076$ & $p=0.002$ & NS \\
\hline
\end{tabular}

Group 1 breast-fed exclusively, Group $2 \mathrm{CM}$ formulas and breast-fed, Group 3 not breast-fed any more at 3 months of age and has been exposed to CM formulas. Median (interquartile range, IQR) and mean (standard deviation, SD) concen- trations of optical densities are shown. Differences between all groups were analysed by Kruskal-Wallis test and between two groups by Mann-Whitney U test 
A
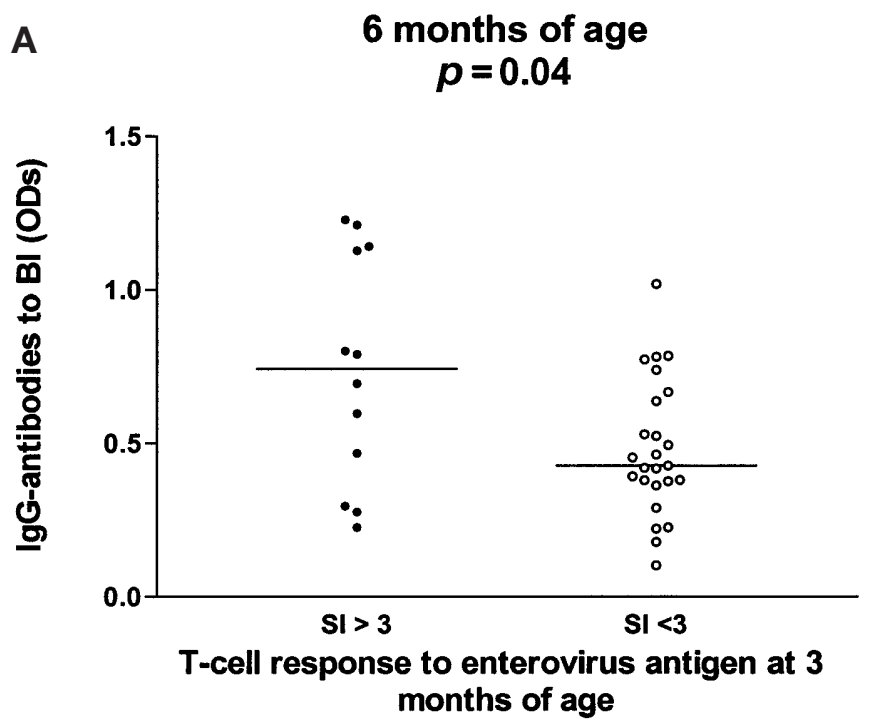

B
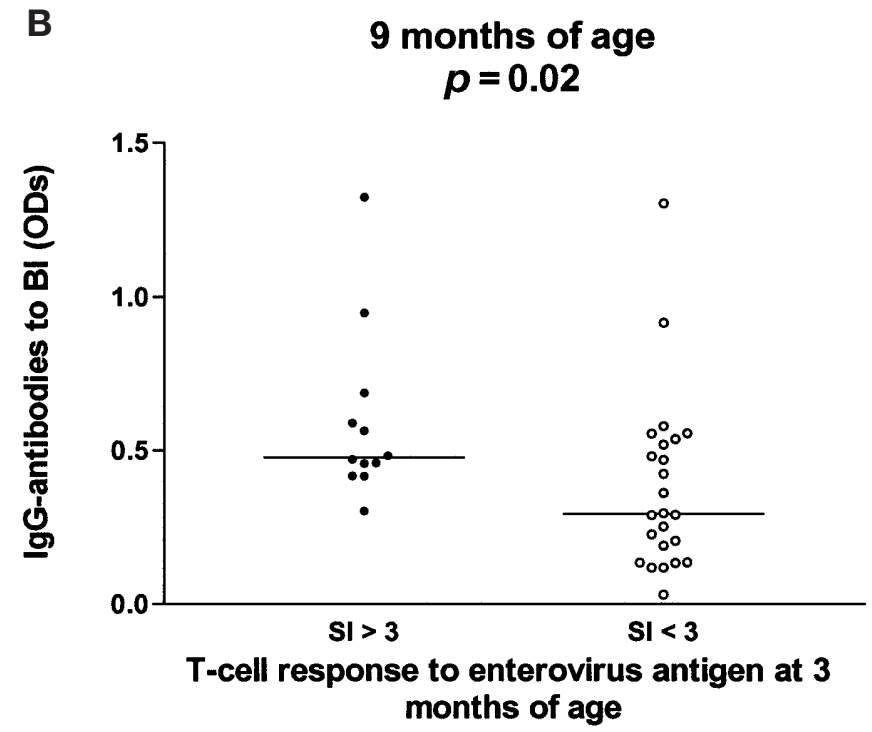

Fig.1(A, B). The concentrations of IgG-antibodies to bovine insulin (BI) expressed as optical density units (OD) at $6(\mathbf{A})$ and 9 (B) months of age in the infants with T-cell stimulation index (SI) below or above three

3 months of life included 5 of $16(31 \%)$ in Group 1, 7 of $25(28 \%)$ in Group 2 and 5 of $12(42 \%)$ in Group 3 . In the 37 infants exposed to cows' milk formulas before the age of 3 months (Groups 2 and 3 ) the infants with a positive proliferation response to coxsackie B4 $(n=12)$ had higher concentrations of antibodies to bovine insulin at the age of 6 and 9 months than the infants who did not show a proliferation response to coxsackie B4 $(n=25)$ (Fig. 1) (median optical density values were 0.742 vs $0.427, p=0.04$, and 0.477 vs $0.293, p=0.02$, respectively). Among the infants who were exposed to cows' milk formula only after the age of 3 months (Group 1), the concentrations of antibodies to bovine insulin did not differ at the ages of 6 and 9 months between the infants with and without a T-cell response to coxsackie B4 at 3 months of age. However, at the age of 12 months the concentrations of antibodies to bovine insulin were higher in the infants who had a T-cell response to coxsackie B4 at 3 months of age than in the infants who did not have T-cell reactivity to coxsackie B4 $(p=0.04)$.

At the age of 6 months a positive proliferation response to coxsackie B4 (SI $\geq 3$ ) was found in 8 of the 15 infants $(53 \%)$ in Group 1, in 6 of the 23 infants $(26 \%)$ in Group 2, and in 4 of the 12 infants (33\%) in Group 3 as an indicator for enterovirus infection during the first 6 months of life. The concentrations of bovine-insulin-binding antibodies did not differ at any age in any group when the infants with and without a T-cell response to coxsackie B4 at 6 months of age were compared.

The relation of bovine-insulin-binding antibodies and virus serology. No increase in $\operatorname{IgG}$ or $\operatorname{IgA}$ antibodies to enterovirus antigens were found between the cord blood samples and serum sample taken at 3 months of age in any of the groups. Only one of the 57 infants had an increase in IgG-antibodies to enterovirus antigens between 3 and 6 months serum samples. Thirteen infants showed an increase in the concentrations of $\mathrm{IgG}$ or $\mathrm{IgA}$ antibodies to enteroviruses between 6 and 9 months of age and 14 infants between 9 and 12 months of age but no differences in the concentrations of BI-binding antibodies were found between the groups divided by serological response to enteroviruses. No differences in the concentrations of IgGantibodies to tetanus toxoid between the groups divided by cellular or humoral response to enterovirus were found at any age.

\section{Discussion}

We confirmed the observation that early feeding of cows' milk formula induces IgG-antibodies binding to bovine insulin $[3,4]$. In the infants exposed to cows' milk formulas before the age of 3 months, increased concentration of antibodies to bovine insulin at 6 and 9 months of age were associated with a positive T-cell response to enterovirus antigen at 3 months age. This suggests that early enterovirus infections enhance the formation of antibody response to dietary bovine insulin. As we studied the difference in bovine-insulin-binding antibodies only in the infants exposed to cows' milk formulas our results were not confounded by the breast-feeding effect.

In this study, serological responses to enteroviruses were seldom detected during the first months of life, whereas positive T-cell responses were detected in $32 \%$ of the infants by the age of 3 months. This reflects the fact that $\mathrm{T}$-cell responses are more sensitive 
markers of enterovirus infections at this age group as maternal antibodies interfere with serological assays. In addition, T-cell assays probably detect a wider spectrum of enterovirus serotypes than antibody assays as T-cell responses cross-react more widely between different enterovirus serotypes [6]. This might also explain why bovine insulin antibodies correlated with enterovirus specific T-cell responses, whereas no correlation was observed with serologically verified infections.

Our results suggest that early enterovirus infections modify the immune responsiveness to oral antigens, such as dietary insulin. This phenomenon was restricted to the infants who had evidence of enterovirus infection already at 3 months of age although 10 of 18 infants with T-cell responses to enteroviruses at 6 months had evidence of a primary infection between 3 and 6 months of age. Enterovirus infections during the first months of life can cause more remarkable changes in the gut immune system than later in life due to the gut maturation, which affect the permeability of the gut as well as the immune responsiveness to dietary antigens. The enhancement of the immune response to dietary antigen is likely not restricted to enteroviral infections only. An increase in the antibodies to food antigens has been reported in rotavirus infections, which cause an increase in the permeability of the gut [7]. Invasive bacterial or viral antigens could also act as adjuvants and enhance the immune responses to food antigens [8]. Viral infections can also change the cytokine environment in the gut [9] and modify the immune responses to oral proteins by so-called bystander mechanism. The appearance of beta-cell autoantibodies including IAA, IA-2 and GADA in association with rotavirus infections have been reported [10]. Alternative explanation to molecular mimicry between rotavirus and islet cell antigens, such as IA-2 and GADA, could be the bystander stimulation of the autoreactive lymphocyte populations in the gut immune system by rotavirus.

Our observation of the primary immunisation to insulin in the gut immune system indicates that insulin-specific immune cells reside in the gut associate lymphoid tissue. The simultaneous occurrence of enterovirus infections, and exposure to cows' milk formula, two epidemiological risk factors of Type I (in- sulin-dependent) diabetes mellitus, could have a synergic effect on the risk of Type I diabetes by enhancement of the primary immunisation to a betacell antigen, insulin.

Acknowledgements: The study was supported by the Academy of Finland, the Novo Nordisk Foundation, and Sigrid Juselius Foundation.

\section{References}

1. Daniel D, Gill RG, Schloot N, Wegmann D (1995) Epitope specificity, cytokine production profile and diabetogenic activity of insulin-specific T cell clones isolated from NOD mice. Eur J Immunol 25: 1056-1062

2. Ziegler A-G, Hummel M, Schenker M, Bonifacio E (1999) Autoantibody appereance and risk for development of childhood diabetes in offspring of parents with type 1 diabetes. The 2-year analysis of the German BABYDIAB study. Diabetes 48: 460-468

3. Vaarala O, Knip M, Paronen J et al. (1999) Cow's milk formula feeding induces primary immunization to insulin in infants at genetic risk for type 1 diabetes. Diabetes 48: 1389-1394

4. Paronen J, Knip M, Savilahti E et al. (2000) The effect of cow milk exposure and maternal type 1 diabetes on cellular and humoral immunization to dietary insulin in infants at genetic risk for type 1 diabetes. Diabetes 49: 1657-1665

5. Lönnrot M, Korpela K, Knip M et al. (2000) Enterovirus infection as a risk factor beta-cell autoimmunity in a prospectively observed birth-cohort - The Finnish Diabetes Prediction and Prevention (DIPP) Study. Diabetes 49: 1314-1318

6. Juhela S, Hyöty H, Lönnrot M, Roivainen M, Simell O, Ilonen J (1998) Enterovirus infections and enterovirus specific T-cell responses in infancy. J Med Virol 54: 226-232

7. Jalonen T, Isolauri E, Heyman M, Crain-Denoyelle AM, Sillanaukee P, Koivula T (1991) Increased beta-lactoglobulin absorption during rotavirus enteritis in infants: relationship to sugar permeability. Pediatr Res 30: 290-293

8. Dahlgren UIH, Wold AE, Hanson LÅ, Midtvedt T (1991) Expression of a dietary protein in E. coli renders it strongly antigenic to gut lymphoid tissue. Immunology 73: 394-397

9. Tough D, Borrow P, Sprent J (1996) Induction of bystander T cell proliferation by viruses and type I interferon in vivo. Science 272: 1947-1950

10. Honeyman MC, Coulson BS, Stone NL et al. (2000) Association between rotavirus infection and pancreatic islet autoimmunity in children at risk of developing type 1 diabetes. Diabetes 49: 1319-1324 